\title{
Shopping and cooking: the organization of food practices, at the crossing of access to food stores and household properties in France
}

\author{
Séverine Gojard ${ }^{1}$ (D) Bérangère Véron ${ }^{1,2}$
}

Received: 25 January 2017 / Accepted: 8 March 2018 / Published online: 29 March 2018

(C) INRA and Springer-Verlag France SAS, part of Springer Nature 2018

\begin{abstract}
This paper explores different ways of organizing food practices in shopping, cooking, and managing leftovers and shows how these relate to sustainability. We conducted an ethnographic study in France based on in-depth and repeated interviews with around 30 'ordinary' consumers aged between 30 and 87 years. We analyzed the interviews using a practice-theory approach and distinguished meanings, materials, and skills linked to food products and eating. We identify four patterns of everyday food practices, each coherently linking specific ways of provisioning, storing, cooking, waste sorting, and other practices. We show how households adopt patterns according to their social characteristics and place of residence and how they switch from one pattern to another according to circumstances. Each pattern comprises some sustainable practices, although not always at the same level. We highlight not only the role of material infrastructure in framing access to food products, but also the necessity to consider temporal organization, financial resources, household size, and social position to understand food practices. Food practices also differ according to definitions of proper eating, which may vary in the long run according to life course events, and in the short run according to the context of meals. We conclude by discussing different ways to promote more sustainable eating.
\end{abstract}

Keywords Environmental concerns · Food consumption · France · Practice theory · Sustainability $\cdot$ Food patterns

Séverine Gojard

severine.gojard@inra.fr

Bérangère Véron

berangere.veron@agroparistech.fr

1 CMH, INRA, CNRS, ENS, EHESS, 48 Bd Jourdan, 75014 Paris, France

2 AgroParisTech, 16 rue Claude Bernard, 75005 Paris, France 


\section{Introduction}

Interest in sustainable consumption is increasing, in public policy discourse as well as in the sociological literature, raising numerous questions about how to promote better practices among households (for instance, Cohen et al. 2013; Keller et al. 2016). Here, we use a practice theory-based approach and look at different levels of food practices (meanings, material, and skills) to understand how they facilitate or impede the development of more sustainable eating. The different configurations of these three levels observed in a qualitative study allow us to identify four patterns of food practices, relying notably on shopping and cooking. From those patterns emerge a variety of routes to sustainability, corresponding to different ways of thinking about sustainable food (considering aspects such as eating local, organic or seasonal products, and avoiding food waste). We also highlight the importance of household characteristics in their adoption of particular patterns and show the impact of social or biographical context on the switch from one pattern to another.

\section{Framework}

The 'practice turn' in sociological theory (Schatzki et al. 2001) entailed new approaches to the analysis of daily consumption (Warde 2005). Among these, food practices are currently under scrutiny as examples of how people integrate (or not) public or private recommendations into mundane activities. This applies to various norms and activities, such as the diffusion of nutritional prescriptions among Danish women (Halkier 2009), the adoption of cooking appliances (Hand and Shove 2007; Truninger 2011), or the management of food waste (Evans 2011a). This theoretical framework found a relevant application in the field of sustainability, because it provided new insights into the understanding of consumption and new ways of thinking about political intervention (Evans et al. 2012). Generally speaking, practice theory focuses on the analysis of social practices, understood as a nexus of 'doings' and 'sayings' held together by collective understandings, procedures, and engagements (Warde 2005: 134). If practice theory is a relevant approach to the study of everyday life because it allows a focus on habits and routines (Warde and Southerton 2012), some material dimensions of these practices often remain out of scope. For instance, the construction of 'cooking styles' by Halkier (2009) relies on cooking skills, shopping practices, and commitment to cooking, but does not consider variability in access to shops according to place of residence. However, the literature has highlighted food supply in terms of the range of food items on sale and their nutritional quality (Holm 2003) and the definition of eating styles pertaining to food shops and restaurants (Johnston et al. 2012). According to Spaargaren and Van Vliet (2000), the 'system of provision' should be considered in relation to domestic consumption. They insist that collective infrastructure determines the availability of opportunities for sustainable practices, and they maintain that the production and consumption spheres are interrelated (see also Oosterveer et al. 2007).

Some studies have tackled the organization of sustainable household food shopping. Wheeler (2012) shows that adherence to fair trade values and the consumption of ethical products do not always coincide and that the presence of fair trade products in the shops is not sufficient to guarantee either their purchase or positive evaluations of their ethical characteristics. Paddock (2017) analyzes daily routines to show how some 
food practices are connected to others and form a nexus locked in by various constraints and routines (for instance, because of work or activity schedules). Thus, the change towards more sustainable practices is more a question of unlocking the nexus to reorganize the practices than one of individual decisions. Brons and Oosterveer (2017), focusing on Parisian students, show that access to sustainable food is an issue that cannot be understood independently from the specificities of student life in terms of housing (little or no space to stock food and shared kitchens) and in terms of rhythms (opening hours of shops and open markets). The interconnectedness of food practices and other practices (working, studying, etc.) appears to be a key point.

Most of the studies anchored in practice theory tend to see individuals as carriers of practices and to underestimate the influence of their social characteristics on their dispositions to adopt a given practice. However, other papers connect concern for sustainable eating to social background. For instance, Carfagna et al. (2014) show that ethical consumption can be considered to frame an 'eco-habitus' specific to consumers with high cultural capital. In this research on specific consumers, for whom food is seen as a vehicle for political action (through boycott or 'buycott'), consumers with high cultural capital appear to be more prone to adopt more sustainable food practices. Paddock (2015) also underlines that 'alternative' food practices can be seen as a way to distinguish farmer's markets and points out the specific arrangement of a place where less privileged consumers feel ill at ease and misplaced. Johnston et al. (2011) analyze the cultural repertoire of ethical consumption to show its proximity to middle-class values and attitudes, thus almost mechanically relegating working-class people out of the sphere of 'proper' consumption. Finally, although some life-course transitions have been identified as turning points in eating habits (Paddock 2017; Plessz et al. 2016; Venn et al. 2017), household structure is rarely considered to be relevant in analyses of transitions to sustainable eating. In line with recent studies (Venn et al. 2017; Wheeler 2012), this article seeks to underline the benefits of examining sustainable eating by considering both practices and individuals. We propose a practice-theory approach and consider the social and demographic characteristics of households to investigate the sensitivity of 'ordinary' households - here understood to be people who are neither activists nor members of any food or environmental association - to sustainability concerns and their ability to implement more sustainable food practices. We understand 'sustainable' in a broad sense, meaning environmentally friendly and part of a competitive and fair economy. Sustainable food practices are not limited to provisioning; they also encompass aspects such as cooking practices (in particular, the use of leftovers) and waste sorting. As sustainable eating does not have a clear-cut and consensual definition, the practices we describe as 'sustainable' are those in line with French public prescriptions, mainly expressed by the French Environment and Energy Management Agency (ADEME) and the Ministry of Agriculture. Such practices involve, but are not limited to, favoring seasonal, local, and/or organic ${ }^{1}$ products, limiting food waste and avoiding packaging. Other dimensions of sustainable eating, such as meat reduction, were not considered to be issues at the time of the fieldwork (2012-2013), either in the French public sphere or in our interviews.

\footnotetext{
${ }^{1}$ In France, organic consumption remains quite limited, although it is growing fast; in 2016, the market share of organic food products for home use was 3.5\%, but it was $1.3 \%$ in 2007 (Agence Bio 2017).
} 
Following Burningham et al. (2014), we use the model developed by Shove et al. (2012) of social practices consisting of materials, skills, and meanings. Our focus on these three elements enables us not only to realize the variety of food practices performed by individuals, but also to understand how their practices change on a daily basis and over the course of their lives according to changes in one of these three dimensions. Through in-depth qualitative research in France, we identified four distinct ideal-typical patterns - coherent systems of both activities and representations. In line with practice theories, we chose to focus on food practices, from provisioning to cooking, stock management, use of leftovers, waste sorting, and composting, although we deliberately illustrate these patterns through the practices performed by participants - or 'practitioners' - in specific contexts. As Halkier puts it, each of the four patterns is 'not individually methodologically based, but only individually exemplified (...) to make it reader-friendly' (Halkier 2009: 364). This typology derives from the identification of different combinations of meanings, materials, and skills. Because those three elements constitute practices, we consider that the typology delineates practices rather than mere ways of shopping and cooking. This approach allows us to examine the contexts and conditions in which households adopt particular practices. Food materials and access to different retail places differ according to where people live; meanings and the definitions of proper food and eating appear to be closely linked to household structure and the presence of children. Food meanings can change in the long term (when the children leave home) or in the short term (when there are guests). Food skills, which result from a process of learning, tend to increase with age; their implementation also depends on circumstances and on available time (Jabs et al. 2007). Thus, we contribute to the debate about stability and change, but on a micro scale rather than a macro one (Warde 2015). In the structural approaches to the sociology of consumption inspired by Bourdieu (1979), social status is considered to be the main determinant of consumption practices, through the notion of habitus, which implies a certain stability of tastes and practices. Therefore, changes in practices are difficult to analyze at an individual level unless social contexts are considered (Lahire 2010 [1998]). In contrast, theories of action based on the vision of an active choicemaking consumer fail to reflect the repetition and routines of mundane food practices and leave social context out of scope. We insist that contextual elements direct household performance toward a given food practice (Warde 2016); the discussion underlines that material, social, and temporal resources are central to reflections on encouraging more sustainable food practices in daily life and shows that individuals can switch from one pattern to another according to changes in their life circumstances.

\section{Methodology}

We conducted an ethnographic study in France, based on in-depth and repeated interviews with around 30 men and women, aged between 30 and 87 years. ${ }^{2}$ Because we wanted to focus on the material elements of food practices, such as retail outlets

\footnotetext{
2 This was part of a larger research on sustainable food practices, funded by Ademe and the French Ministry for Economy, Environment and Sustainable development. We thank Ana Perrin Heredia, who conducted the interviews, and the other members of the team: Sophie Dubuisson-Quellier and Marie Plessz.
} 
and household equipment, we chose to compare two different settings: an apartment building in a northern district of Paris and an outlying neighborhood of a small town in the north of France (that we shall call 'Noraville'). By comparing two locations, we highlight the importance of supply structure in determining the range of available shopping items, and we show how food provisioning is organized within this range (where local or organic food items are not evenly distributed) (Spaargaren and Van Vliet 2000). In these two locations, fieldwork was conducted within a limited area to enable comparisons between households with similar food provisioning options and similar collective equipment. The Parisian location features a wide range of shopping facilities within walking distance, from strongly discounted to high-quality supermarkets, frozen food shops, convenience shops, bakeries, and a large farmer's market running twice a week. Moreover, Paris offers a varied range of specialized shops, accessible by public transport or by car. The Noraville neighborhood is characterized by far fewer options accessible by foot, and the small nearby farmer's market operates only once a week. A couple of supermarkets in the surrounding areas are accessible by car. Because rural areas are not far away, alternative options such as buying directly from farms are more easily available than in Paris, although they also require a car trip.

Committed or militant consumers, who have been clearly identified in recent sociological literature (Dubuisson-Quellier 2009; Halkier and Holm 2008; Hughner et al. 2007; Micheletti and Stolle 2012), were deliberately excluded. We focused on 'ordinary' consumers recruited through personal contacts and snowballing on a residential basis. Moreover, to avoid over-reporting, participants were told the study dealt with ordinary food consumption practices in general-how they shopped, stored food, prepared meals, ate, used leftovers, or did the washing up, with no specific mention of sustainability issues. The words 'sustainability' and 'sustainable' were not explicitly mentioned by the interviewer to avoid biased answers. Each of the participants was interviewed twice to four times, for several hours each time. The interviews were recorded and transcribed, followed by content analysis conducted by members of the research team.

As Evans (2012) underlines, the home is the most appropriate place to study everyday consumption, yet interviews are not sufficient to capture both the 'doings' and the 'sayings' of consumers. Photographing the various domestic spaces relating to food practices - rooms (kitchen, dining room, and living room) and storage places (cupboards, fridges, freezers, closets, sculleries, and garages) - was used as a complementary investigation device. Inventories of food products and equipment indicated discrepancies between reported and effective practices (notably concerning the use of convenience foods). Although the sample is not representative, both districts are socially mixed, so the ages of the people interviewed, their levels of income, and their household compositions vary greatly (see appendix).

\section{How meanings, materials, and skills organize food practices}

The dividing lines among the food practices reported by participants, related to the differentiated meanings, materials, and skills that characterize them, led us to build a typology of food patterns, characterized by similar everyday practices, and structured by similar kinds of resources, constraints, and socio-cultural properties. 
Two main meanings attached to food can be distinguished. The first is selforiented and holds proper eating to be frugal, healthy, and simple; the second is family and children oriented and combines health considerations with a concern for variety, pleasure, and abundance. Each of those two meanings is associated with different food practices, according to variations in materials or skills. The first meaning - frugality - falls into two patterns according to access to retail outlets and the material aspects of the practices, whereas the second one-abundance-falls into two other patterns depending on culinary skills and their mobilization for daily eating (Table 1).

\section{Food meanings}

Although health concerns and a desire to follow nutritional prescriptions are widely shared, the norms of appropriate eating are not the same for all households; this depends on the members' ages and the family situation. Jackson et al. (2006) show that notions of 'value' and 'quality' are not defined the same way by all consumers. We find a similar result; all the interviews underline a concern for proper and healthy eating, but the meaning of this differs.

Thus, the older participants - those who are retired, in their $60 \mathrm{~s}, 70 \mathrm{~s}$, or $80 \mathrm{~s}$ associate health with frugality. In addition to the strong moral connotations of the moderate 'use of money, goods and resources with a particular emphasis on careful consumption and the avoidance of waste' (Evans 2011b: 552), here frugality also conveys simplicity and even monotony, because unelaborate, quickly prepared, and recurrent dishes are a way of keeping daily meals light and balanced:

The day-to-day routine is really one of extreme simplicity. (Vivianne, 60, primary schoolteacher on sick leave, married with two independent children, Paris)

Soup is my basis. Soup, pastas, rice, those are my bases. (Monette, 65, divorced with three independent daughters, former journalist, Paris)

In other words, to older practitioners, proper eating in daily life is both healthand self-oriented. They share high levels of shopping, cooking, and organizational skills. These shared skills are probably linked to an age effect (as aging parents, they may have acquired and improved their skills through time), and a generational effect, explaining their high propensity to cook at home from scratch. Convenience products are reluctantly purchased and discredited (for example, pre-packed salads are compared to tasteless paper). Frozen products, with a taste described as fairly poor-i.e., less tasty than fresh, homemade products - are viewed as last-minute stop-gap solutions with practical benefits and are bought in limited quantities.

Young parents, on the other hand, associate health preoccupations with their children's health rather than their own and insist on variety and abundance. Mothers, as the main caretakers, make efforts to alternate treats and healthy meals: repeated favorite dishes and new ones. Nutritional concerns outweigh environmental ones, especially when children are very young. Mothers aspire to engender healthy eating habits (Cairns et al. 2013; Carrigan et al. 2006): 


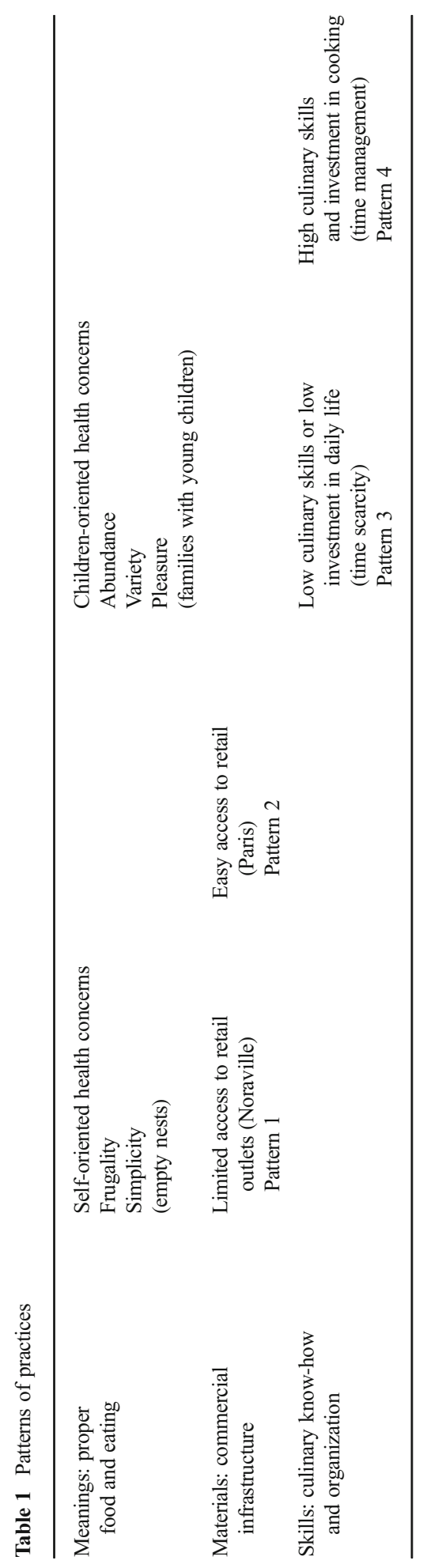


My food practices are very strongly determined by the fact that above all I cook for my children. When I cook for myself only, it's completely crazy. I can feed myself with a jar of Nutella! But I really try, on a day-to-day basis, to have the children eat properly so they get used to... eating things that are not processed. So that they see what vegetables look like, what fish looks like... (Corinne, 45, divorced, two children aged 8 and 13, researcher, Paris)

However, those concerns often appear to be difficult to implement in daily life. Purchasing decisions are influenced both by the price and preferences of family members for specific products and brands. As Hamilton (2012: 83) reports concerning clothing among low-income families, compliance with children's favorites is seen as part of 'good motherhood'. Indeed, mothers play a central role in food preparation and face strong family constraints, notably because the tastes and needs of all family members have to be taken into account in provisioning choices as an expression of family care (DeVault 1991; Miller 1998). Everyday meals are simple and children oriented, with the same 'successful' recipes being repeated over time-for instance, pastas, croque monsieur, pizzas, quiches, or hamburgers. Improvising or trying new dishes is risky and may lead to food waste. 'Simple' and 'balanced' are recurrent words in the interviews:

Meals need to be balanced, above all.

What does 'balanced' mean for you?

Balanced, hum, for me, a balanced meal is proteins... Well, fish, meat, green beans... starchy foods... cheese, and fruits. For me, that is a balanced meal.

And you do that daily?

Well, we try to... For my girl, I try to... inculcate that in her. It's not easy, because sometimes she does not want to eat green beans, or she does not want to eat... We try, we try but it's true it's often only in theory! (Nadège, 33, married, one daughter aged 2 , pregnant, interior designer, Paris)

In addition to health benefits, homemade food is favored because of the preference of family members for prepared food, although time constraints do not always allow for everyday home cooking. Convenience foods (chicken nuggets, fish fingers) are purchased and enjoyed by the children as a treat. Convenience foods are also valued for the time benefit in those households facing strong time constraints. We often observe discrepancies between the meanings attributed to food-which ideally should be healthy, cooked from scratch, and in line with nutritional recommendations - and the practices of eating, which are also influenced by children's tastes, money, and time constraints.

Thus, the first division concerns the contrasting meanings ascribed to food practices, which depend on age as much as on household composition. Yet, even for elderly households, norms of abundance can predominate for some meals; everyday routines shift to more elaborate cooking on special occasions, particularly when children, friends, 
or neighbors come home for a meal or for holidays. More elaborate dishes are prepared, in contrast with the plain and sometimes monotonous everyday meals. The meanings of eating then change in specific contexts, particularly meals with guests, characterized by longer preparation time. What appears to be a proper meal for everyday life has neither the same structure nor content as a proper meal with invited guests.

These two groups based on food meanings do not exhibit homogeneous food practices, because they differ regarding the other dimensions of practices: materials for the elder group, skills for the younger.

\section{Food materials}

Retail outlets distinguish between the practices of aging participants: the two patterns correspond to the two locations of fieldwork. As mentioned above, the groups' provisioning options differ greatly. Thus, older participants in Paris with greater financial and time resources use a wide range of provisioning options to seek quality and good value for money. Concern for gustative quality, rather than environmental motivations, favors the purchase of local foods and shopping in specialized food shops or at farmers' markets. In Noraville, so-called 'ethical' produce, encompassing numerous definitions - organic, fair trade, free range, local, and so forth (Johnston et al. 2011) - is mostly available in supermarkets through labeled food products. However, alternative provisioning is implemented insofar as it is easily integrated into routines and facilitated by proximity to rural areas.

\section{Pattern 1: frugality and short-range supply}

In the first pattern, located in Noraville, food provisioning is organized around weekly stocking up at the nearby supermarket, done by car, because few food shops are within walking distance. Some supplementary shopping locations are used, mainly other supermarkets where specific products are routinely purchased and are cheaper or considered of better quality. Food choices are highly routinized. Meals are frugal; the cooking time is quite short and homemade food prevails. Food waste is said to be scarce, and leftovers are easily re-used in the usual ways. In addition, perishable food products are purchased in small quantities, which may be another reason for limited food waste.

Noteworthy is the limited knowledge about sustainability labels; very little attention is given to 'ethical eating' (Johnston et al. 2012). Conversely, branded products are strongly valued and routinely favored over entry-level products, which are cheaper but considered to be of lower quality. For instance, Roselyne (60, divorced, two independent children, specialized helper in pre-school, Noraville) does not cook very much for herself, but she insists that she values quality. Almost all her provisioning is done at the nearby supermarket. She rarely eats meat, but when she does, she buys it from the meat section of the supermarket, and asks for quality choice cuts:

I don't eat much. So I buy... I treat myself, I buy myself something nice... If I buy pork, I... I like eating fillet, I won't go for... for something cheaper that I won't enjoy. 
This specific criterion for meat purchases does not refer to labels. Quality assessment practices are based on the selection of the cut and on cost; high price is interpreted as a guarantee of quality. Thus, strategies for quality are routinely implemented in the supermarket. Thrifty choices are made between branded and private labels, entrylevel and quality products, fresh or frozen produce and other decisions according to the products, their planned use and the shopper's past experience. Nonetheless, discounted, short-dated products or private label brands are avoided when considered of poor quality, i.e., unhealthy or distasteful.

Moreover, maintaining a kitchen garden and buying fresh and local products through short food supply chains are common. Yet, these eco-friendly practices are not related to environmental motivations; they are incorporated in daily routines as cost-saving practices. Hence, households with limited incomes seeking quality and good value for money may have sustainable food provisioning practices, although they do not describe them as such. This disconnection with environmental issues may be explained by the fact that at shopping locations such as farmers' markets or farms, local food products are not promoted or marketed as 'green'. To summarize, this pattern is characterized by limited environmental concerns but eco-friendly practices. This pattern mainly applies to one-person households and couples whose grown-up children have left home. These households have few time constraints, and the oldest householders have long-established food habits with low use of convenience foods. They have limited financial resources; their food budget is scant, with substantial attention given to price per kilo and value for money. Among such couples, men do not voluntarily shop or cook, as these are viewed as timeconsuming chores that may be associated with the traditional division of domestic work among low-educated working-class people.

\section{Pattern 2: a diversified supply mobilized to meet the demand for quality}

The second pattern, located in Paris, is characterized by diversified provisioning locations and frequent shopping, favoring fresh, quality products. Provisioning is multi-modal, and substantial time is allocated to this activity. The variety of shopping places and the financial resources allow more varied shopping practices than in the preceding pattern. We also noticed that culinary sociability is more developed than in the former pattern, based on exchanges of shopping place recommendations, recipes, techniques, and invitations. This sociability is the basis for conspicuous practices that are readily detailed in the interviews.

Quality is associated with specific food shops, whereas in the former pattern, quality was constructed within the supermarket. The frequency of shopping sequences and the extended and diversified area of provisioning are part of a thoughtful strategy to access quality products at good prices, in the vicinity and beyond. Participants go shopping at several supermarkets and purchase different products according to price and quality differences. Regular and frequent shopping sequences to the local market lead to indepth knowledge of stalls and storekeepers, sometimes known for decades. Thus, careful selection of the provisioning places and the numerous conversations participants have about shops and recipes suggests distinctive practices (Bourdieu 1979) that rely on a sense of 'knowingness'. Paradoxically, participants underline their concern for good value for money; they insist that their habits are reasonable, arguing that they 
would not purchase overpriced products. Yet, their provisioning practices may be ostentatious, especially when practitioners have had ascending social trajectories. Yves (69, married with two independent children, former company vice-president, Paris), who did not graduate with a baccalaureate but 'got by fine' with a successful career, is 'passionate' about food. He owns a whole shelf of cooking books, follows several cooking websites, and exchanges recipes with his friends. Before his wife developed cancer, they would have guests for meals two to three times a month. He pays little attention to prices and has no idea about his weekly food budget. He goes to the supermarket as rarely as possible; every Saturday morning he drives to a far-away fishmonger's shop. He sometimes goes across Paris to buy spices in 'a tiny store packed with exoticism' and purchases vanilla pods on the Internet.

Moreover, routinization as a time-saving device and as a relief from reflexivity (Halkier 2009) relies on the use of brands and quality labels as a sign of gustative quality and/or safety. Geographic origin is more often mentioned than by people following the previous pattern, especially for French poultry and meat (Bresse chickens, Chalosse beef) and Nordic smoked salmon (from Scotland or Norway, considered to represent different levels of quality). Sustainable labels are frequently used for poultry and eggs; the term 'free-range' is more common than 'organic'. More generally, the purchase of organic products is quite limited but regular. Their high prices are mentioned as a major barrier, but do not prevent purchases. As expected, the private benefits allocated to organic foodstuffs, in terms of health and taste, are more decisive for consumers than are public benefits, environmental benefits, animal welfare, or similar considerations (Lamine 2008).

Nevertheless, participants express 'green goodwill' and voluntarily implement specific green provisioning practices. However, this 'green goodwill' is both limited and reflexive. It only involves specific products, and it implies practical concessions to their own 'rules' regarding environmentally friendly consumption. For instance, fair trade products may be tried and viewed as a source of personal gratification, in that this label, unlike the 'organic' label, is perceived as 'ethical' in a broad sense (Johnston et al. 2012). Pierrette (65, married with two independent children, former primary school teacher, Paris) expresses the tension between altruistic motives and pragmatic considerations of quality and taste:

Several times, we decided to purchase fair trade products; it is a right thing to do... and it gives you a good conscience, sometimes, to buy these products, but every time we've been disappointed! I mean, really. The chocolate is not good, we think! Actually we are a bit hard to please with chocolate. The coffee was not great... The tea, not good at all... Anyway, every time we tried... So, we gave up.

This example suggests that privileged aging consumers are ready to incorporate ethical concerns into their consumption routines as long as the gustative quality of the ethically labeled product is equivalent to that of the conventional one. This concern for taste may explain why purchasing decisions concerning household products more often take into account environmental matters than they do with foodstuffs. Some sustainable practices are routinized in everyday life, such as using as little detergent as possible, or recourse to traditional household cleaners such as spirit vinegar and baking soda, for 
which cheapness and efficiency are often underlined. However, green washing liquids and washing powder, soap nuts and so on, are not routinely used, because they appear to be less efficient than conventional products and may even be negatively characterized as 'chemical' or 'toxic'. Many participants point out their inconsistent attitudes, combining efforts towards greener practices with the use of harmful products. As Wheeler (2012: 137) suggests, incoherent practices should be linked to practical 'doabilities' in daily life, rather than to a lack of information or motivation.

Family constraints are limited, and everyday routines are characterized by few unexpected events. The departure of children from the parental home is associated with reduced food purchases, better management, and less food waste. The amounts bought and prepared are well adjusted; freezing is used to extend the lifespan of the produce; leftovers are used in rather elaborate and repeated ways, but also in renewed dishes, as in the preceding pattern. Cooking skills also explain limited food waste. They facilitate the use of potentially wasted food products and enable the same ingredient to be used in several meals, thus avoiding the monotony of having the same dish several times in a short period.

This pattern is mainly found in households belonging to the same age group and generation as those in the preceding pattern, but these householders live in Paris and have more financial resources. Each couple's roles and responsibilities in relation to food are quite stable and clearly defined and are more equally shared than in the previous pattern, which is followed by less educated couples. Men are significantly active in provisioning and cooking (Kan et al. 2011; Larmet 2002; Szabo 2012). Their greater contribution to food practices also explains the wider diversity in provisioning.

Those two patterns differ mainly in terms of their location and access to retail outlets, but the lifestyles of the households also differ. Although they are not in a privileged neighborhood, the Parisian households have more money and better educational qualifications, and they display more social resources, leading to conspicuous consumption. In Noraville, food sociability seems less evident, and the changeover from simple daily eating to more elaborate meals with guests is less frequent.

\section{Culinary skills}

The two following patterns of food practices share many characteristics: they mainly involve active middle-class couples with children who face strong temporal, financial, and familial constraints. As described above, they share common meanings in that proper eating is children oriented, varied, and pleasurable. Moreover, those practitioners seem to share a pronounced sense of time constraints, which are recurrently mentioned to justify grouped purchases at a limited number of shopping locations, even for those who live in Paris and could benefit from a diversified food supply. As described by Jabs et al. (2007), time scarcity in families with children results in different strategies of time management and food organization. Culinary and organizational competences, as well as the time devoted to daily cooking and the tendency to cook from scratch, are all clearly differentiated between the two patterns.

Culinary knowledge, techniques, and practical know-how appear to be unequal, as are organizational skills, i.e., the ability to plan varied and balanced meals to respond to unexpected changes in the number of mouths to feed and to manage leftovers. It is also 
the propensity to use these skills in everyday life that differs greatly among young active parents, revealing how they prioritize homemade food (Moisio et al. 2004).

\section{Pattern 3: strong constraints and low investment in cooking}

In this third pattern, limited time is devoted to shopping and cooking; provisioning habits rely on stocking up at the supermarket, conducted by car around once a week, usually with partner and children. They are sometimes supplemented with purchases at closer supermarkets or local shops (butcher shop or delicatessen) for better quality products, such as fresh vegetables, meat, or fish. Provisioning at the nearby market is less regular, and purchases from local producers are far fewer than in patterns 1 and 2. Thus, the food budget is substantial and family oriented. Provisioning activities are mainly conducted by women, while men tend to have responsibility for specific food products such as bread or meat.

Quality and origin labels are given far less attention than in the previous patterns. Generally, organic purchases appear to be an additional constraint in an already strongly constrained mode of food shopping. Participants tend to point out that the purchase of fresh products is not even routinized, in spite of strong adherence to nutritional prescriptions, and fresh vegetables are associated with healthy, 'proper' cooking (Plessz and Gojard 2015).

Well, the [organic label] is something that really doesn't matter to me. I think that buying fresh products is already... a big gesture (she laughs). (Corinne, 45, divorced with two children aged 8 and 13, researcher, Paris)

In this context, 'local' products, widely defined as such, appear to have more legitimate and responsible attributes than organic ones, and are an alternative to this label, which is often viewed as untrustworthy and commercial. Likewise, seasonality and origin are valued for fruits and vegetables, for both taste and health reasons rather than environmental ones. Brands, on the contrary, are strongly valued and relied on, although the choices appear to be less stable than in patterns 1 and 2, with experiments and shifts from one brand to another, or to a quality label. Selected brands may either be the object of a family consensus, or of thoughtful attention to one member of the family. Convenience foods are far less discredited than in patterns 1 and 2, especially as prepackaged salads or frozen vegetables may be a way of increasing vegetable consumption. Their timesaving and practical benefits are valued; their purchase may also be a way of dealing with lack of culinary skills. For instance, Valérie (42, remarried with two children aged 10 and 20, employee in a home care association, Paris) only buys fresh potatoes and chicory: all the other vegetables purchased are frozen, unprocessed but pre-sliced, as she does not know 'what to remove or peel'. However, a sense of guilt (Thompson 1996) may arise from a comparison with alternative and more legitimatebut tedious - ways of handling food.

In this pattern, practitioners report that they do not cook on a daily basis, but rather for special occasions, or during the weekend. The mothers interviewed prepare dishes that do not need much preparation, or cook large quantities for several meals, or reduce meal preparation by using convenience foods, or rely on their partner to prepare the evening meal. Preparation time is limited: feeling 'pressed for time' (Southerton and Tomlinson 
2005 ) is frequently mentioned as a source of discrepancy between legitimate and 'proper' food practices and effective ones. These practitioners express strongly self-deprecating opinions about their own cooking skills, which demonstrates that the use of pre-prepared or processed products is commonly disapproved of, although such products do require cooking skills (Short 2006). In contrast, homemade meals, although rare and related to specific temporalities, are associated with rewarding efforts (Moisio et al. 2004).

Strategies to limit food waste are different from those implemented in patterns 1 and 2. Leftovers are re-used in less elaborate and more flexible ways and are more often 'forgotten' in the fridge. The amounts to prepare are not always well calibrated, with doubts expressed about the right quantity to cook. Last-minute changes in planned patterns are a source of mismatch between what is purchased, cooked, and consumed (Evans 2011a). Thus, constraints on family coordination derive not only from the children's unpredictable tastes and schedules, but also from the tensions between concerns about food waste and those of food safety (Watson and Meah 2013), particularly apparent in households with young children. Co-ordination between partners may also be another source of food waste, especially when both partners are involved in shopping. Tensions may arise from differences in opinion concerning what and how much to buy, over the disposal of leftovers, or over responses to use-by dates. Environmental prescriptions are far less easily co-ordinated in food provisioning and cooking than in pattern 2 .

Other daily practices convey green goodwill in a more profitable way. Green goodwill is more explicitly voiced than in pattern 1; as in pattern 2, it is expressed in choices of household products rather than food. Basic but efficient products are favored, such as spirit vinegar, bleach, water, and soap, and these indicate a concern for simplified housework. Personal experience and 'tricks' inherited from one's parents are mobilized to implement an everyday economy of simplicity. The purchase of various and elaborate cleaning products and wipes tends to be reduced in favor of eco-friendly multi-use products, which are also cheaper. Therefore, this pattern of food practices is characterized by limited environmental concerns and eco-friendly food practices, although thrifty everyday habits inherited from parents are actually sustainable.

\section{Pattern 4: strong constraints and high investment in cooking}

Whatever the scope of provisioning options, shopping practices in pattern 4 are similar to those in pattern 3-i.e., mostly grouped purchases. More generally, the practices mainly differ from those of pattern 3 in that they require greater cooking skills, i.e., more homemade dishes are prepared and more time is devoted to cooking in everyday life - although participants insist on quick preparation — and more organizational skills are required, leading to more efficient time management strategies (Jabs et al. 2007). Mothers take pride in their children's taste for homemade food, and in their own ability to provide fresh healthy meals:

It's a real pain, but at the same time I am quite happy, because... my older son in particular... he notices when I haven't cooked it, and he likes it better when it's homemade stuff. (Corinne, 45, divorced, with a partner and two children aged 8 and 13 , researcher, Paris) 
Culinary skills are also organizational: freezing products or leftovers is common, as well as using leftovers to cook a new dish. For instance, Catherine (45, with a partner and one child aged 5, teacher, Noraville) explains that her habit of splitting various types of meat into several portions and freezing it is a way of avoiding eating 'the same thing all the time'. Likewise, as in patterns 1 and 2, practitioners have routine 'tricks' to use up leftovers, although in less elaborate ways than in pattern 2. Corinne (45, researcher, divorced, with a partner and two children aged 8 and 13, Paris) mentions 'bottom-of-the-fridge salads'-'you put all that's left in it'. Finally, whereas in pattern 3 , participants explain that because they have children, they rarely invite friends for a meal, here parents still do, and spend time preparing meals - although less often than in pattern 2 .

Yet, just like in pattern 3, these respondents have a critical opinion of their own skills and tendency to repeat the same dishes. They regularly refer to someone in their family environment (their mother, their mother-in-law, their sister) described as an accomplished cook, only to point out their own incompetence and lack of creativity. As underlined before, this pattern also involves parents in their 30 s and 40 s with temporal, financial, and family constraints.

\section{The social context as a clue to understanding the adoption of a practice}

\section{Household characteristics}

By assessing the participants' narratives according to the dimensions of meanings, materials and skills, we identified four ideal-typical patterns of everyday food practices, each coherently linking specific ways of provisioning, storing, cooking, waste sorting, and other practices. Through this typology, we show that not only are food practices embedded in material frameworks and structured by access to food supply circuits, they are also strongly shaped by the socio-economic and demographic characteristics of the households, and by the unequal constraints and resources of practitioners.

This typology underlines that food habits cannot be isolated from their material and social context. The first two patterns differ mainly in terms of location, which implies different food supply organizations, and according to the socio-economic characteristics of the households, as those who live in Paris have higher incomes and educational qualifications. These patterns enhance the structuring effect of supply; Noraville residents with high incomes and educational qualifications could not adopt the provisioning and cooking styles displayed in Parisian pattern 2. Although the snowballing method led to rather homogeneous groups of participants in each fieldwork site, the locations themselves were purposively chosen because they are socially mixed and we did not identify 'prototypical eating styles' in the interviews, unlike Johnston et al. (2012). Significantly, patterns 3 and 4 are not related to a specific kind of commercial supply, and they apply to both fieldwork locations. Thus, although supply may have a structuring effect on provisioning practices, as shown by patterns 1 and 2 , it is not sufficient to explain them fully. Patterns 3 and 4 differ from patterns 1 and 2 , because they apply mainly to households with working parents and young children, whose time constraints 
structure their daily timetables (Southerton 2006). For them, homemade cooking requires time availability and minimal skills and is favored by financial constraints. Processed products, which are both fast to serve and storable, are a way of handling unexpected changes in routines and time constraints, but they may also constitute treats (Miller 1998). Such products are only reluctantly bought and used by households in the two preceding patterns, where a generational effect combines with more time and better cooking skills.

The last two patterns are both typical of family households, whereas patterns 1 and 2 concern couples or one-person households. Patterns 3 and 4 share common temporal and financial constraints, and common concerns about the children having balanced meals and healthy eating habits. Yet, as shown above, the time spent on daily meal preparation and the ability to cook from scratch differ greatly. The degree of investment in daily cooking tasks appears to be linked not so much with time resources as with the ability to organize and fit cooking tasks into a very busy timetable (Jabs et al. 2007). The mothers who are strongly invested in cooking benefit from specific social dispositions that may partly explain the different patterns of practices, despite similar constraints. First, they more often have flexible work schedules or the opportunity to work at home, which facilitates the integration of cooking tasks into a tight timetable; or alternatively they have periods of time free from cooking tasks, either because family constraints are momentarily suspended (for instance, when children are at their father's place for divorced mothers) or thanks to their organizational skills (leftovers may be routinely used for several meals). Moreover, practitioners in pattern 4 more often express self-satisfaction, which is directly related to the positive reactions of family members when home-cooked dishes are served. Thus, the investment in time required to prepare elaborate recipes is not rewarded in the same way. Cooking for children or teenagers, who may openly express preferences and distastes, entails more explicit gratification than cooking for toddlers or young children. Finally, in addition to different organizational resources and different household compositions, social dispositions inherited from childhood seem quite decisive in two apparently paradoxical ways. Women explained their desire to give their children homemade meals by referring to their childhood habits of being served homemade food, simple yet cooked from scratch. However, describing their mothers as 'good cooks' who were compelled to devote a lot of time to cooking tasks was also used as an argument to justify their own disinterest.

The four ideal-typical patterns we identified recall that when dealing with sustainable eating, standards and food practices perceived as 'proper' should be analyzed with regard to everyday realities of what is pragmatically possible (Sahakian and Wilhite 2014), because individuals are unequally endowed with material, social, and temporal resources. Greater attention should also be paid to the contexts of performance, as 'practices configure performances, and practices are reproduced and stabilized, adapted and innovated, through performances' (Southerton and Yates 2015). These contexts, whether material or social, contribute to explaining why individuals may 'switch' from one pattern of practices to another, according to locations and temporalities, when the resources and constraints of daily life are reshuffled. From this perspective, patterns 1 and 2 show that beyond financial inequalities, disparities in terms of access to provisioning options also help to differentiate food practices between households with the same temporal resources. Patterns 3 and 4 reveal that unequal culinary skills, as much 
as unequal dispositions to mobilize these skills, explain why similar constraints do not lead to homogeneous everyday food practices.

\section{Transitions and change between practices}

Our results also show that, throughout the life cycle or according to circumstances, practices can be located in one pattern or another.

For instance, Nathalie (45, Spanish teacher, with a partner and one 5-year-old boy, Noraville) adopts practices that are mainly situated in pattern 3. She devotes as little time as possible to cooking and says she has been 'obliged' to cook since the birth of her child. Her main motivation is to provide him with a healthy and varied diet, including vegetables, although he is a fussy eater: 'it's very difficult to feed this child'. Most of the time, she repeats a few recipes that she knows by heart and that are very fast to cook ('when I come home from work, I don't feel like spending time cooking', she says). However, when she has guests, she devotes more time to meal preparation and switches to pattern 4 :

For Christmas, my parents came over, we had made a meal... [...] They arrived on Monday, and we spent the whole day making 'verrines' with small stuff, a little sophisticated. [...] I try to cook things that are a change from daily meals... Starters, I never have any ideas, so I search in recipe books.

For Nathalie, cooking is not a priority in everyday life, but she has inherited norms of invitation that render a strong investment in meal preparation necessary when there are guests. This investment is favored by specific temporalities (holidays or weekends), when time is less constrained.

In other cases, the lifetime perspective offered by retrospective interviews shows how food practices evolve with monetary resources and with household size. Monette (65, divorced with three independent daughters, former journalist, Paris) has been living on her own for 4 years. Being retired, she has been confronted with a drop in her income and says she has to be careful with money. Although she lives in Paris and has access to a diverse food supply, in everyday life her practices are close to pattern 1, marked by frugality and simplicity. She goes shopping on foot, in several nearby supermarkets and has stopped the 'big fill up' she used to perform by car at a larger outlet when her children lived with her.

To save money, she buys fish once a month, whereas she used to serve fish to her daughters twice a week. She hardly buys any meat (she finds it too expensive from the butcher, and too poor quality from the supermarkets) except when she invites her grandchildren.

Alone, I do not eat meat. From time to time, I'll buy some pork or chicken. But red meat, it's over. Only when the kids are here do I have some, because they like it.

The visits of children or grandchildren may also involve the use of domestic appliances that have been given up since they left home. Monette, for instance, explains that she rarely uses her large freezer for herself, and only fills it when she expects to host her three grandchildren. 
To summarize, when her three daughters used to live with her, Monette adopted practices ascribed to pattern 3: grouped food purchases, children-oriented meals with a concern for variety, low cooking investment to suit time constraints linked to her occupational investment. Now that she is retired and lives alone, her daily practices are more frugal and close to pattern 1 despite living in Paris, because she cannot afford to benefit from the diversity of food retailers. However, when she invites her family for a meal, Monette's food practices belong to pattern 4, with higher expenses and a renewed investment in family recipes that are said to be 'traditional'.

It's a cake without any baking. You prepare it with small biscuits (Thé Brun) and a butter cream. You dip the biscuits into coffee; and one layer of biscuits, one layer of cream... it's very rich! And you sprinkle cocoa powder on it. It's very, very good. You make it the day before serving. So there is this cake for every family party. It comes from my mother's side.

At such family meals, the serving of food made from inherited recipes enhances the festive dimension of the gathering. Close attention to short- and long-time modifications in lifestyle allows us to understand how activities fit into one pattern or another. Short-term modifications to meal contexts, when they alleviate time constraints, can entail switches from patterns 3 to 4 . Switches from patterns 3 and 4 to 1 or 2 are also frequent over longer time spans. The skills and the ability to use them are subject to change resulting from learning and accumulation, or conversely to the progressive disappearance of techniques that are no longer used (for instance, after the children's departure).

\section{Conclusion}

In this paper, we showed that the organization of supply has a structuring effect on food shopping, but this effect is modulated by the constraints and resources of each household. Social properties, time, and budget constraints all have impacts on the degree to which consumers subscribe to different norms and standards related to nutrition, but also to factors such as commercial labels and organic standards. Our focus on food practices, from shopping to waste management, allows us both to distinguish different scales - identifying factors that pertain to the retailing system and to the household structure - and to show how they are intertwined; for instance, a given location does not entail a unique pattern of food shopping.

Our results are twofold. First, they show how different ways of implementing sustainable food practices are linked to shopping and cooking patterns. Second, they allow us to understand how social properties and life circumstances contribute to the adoption of one pattern or another. Thus, sustainability considerations are distributed across meanings, materials, and skills. Meanings, in our interviews, are mainly linked to health and nutrition concerns, while sustainability themes remain less relevant. However, this lack of concern about sustainable food is not incompatible with ecofriendly food practices, such as buying seasonal, local or organic food, or avoiding food waste (Dubuisson-Quellier and Gojard 2016). Food materials, here mainly apprehended through shopping locations, put unequal stress upon sustainability. In 
supermarkets, some labels serve as an index for sustainable foodstuffs, whereas in smaller-scale retail or open-air markets, sustainability appears to be connected to specific shops (for instance, those selling organic or local produce). The mobilization of culinary skills to prevent food waste or to cook fresh food may also be related to sustainable food practices. No clear hierarchy emerges from the different patterns according to sustainability, as all of them include some ways of managing food that are coherent with sustainable goals. Rather, it should be underlined that different routes to sustainable food practices are privileged for each pattern. In pattern 1, frugality and avoidance of food waste, kitchen gardening, and access to locally produced food are paramount. Pattern 2 emphasizes concern about the origin of food, purchases of fresh products, often from the market, and a mobilization of culinary skills. In pattern 3, concerns about fresh food for the children and about budget constraints dominate, and in pattern 4 , cooking from scratch and re-using leftovers are primary considerations.

Furthermore, the detailed interviews allow us to understand how individuals can switch from one pattern of practices to another, according to changes in social context (Halkier and Jensen 2011). The theoretical framework of practice theory highlights the performative role of practices, and here, we can see very clearly that individuals may follow one practice or another at different periods of their life or in different circumstances (for instance, everyday meals versus meals with guests). We restate here the distinction between practice as entity and practice as performance (Warde 2005); the patterns describe the organization and routines that define practices (as entities), and the performance of the households follows different patterns according to their circumstances. Changes in food meanings, and in the perception of proper food, seem to be linked to the stage of the lifecycle, and with the relevant perception of health as selforiented or children oriented. In this paper, changes in the material elements of food provisioning have mainly been captured through shops, then linked to the location of the home, but they also encompass household equipment, appliances, and so on, which may play a role in the management of leftovers (Shove and Southerton 2000). Changes in the food skills and in the propensity to use those skills appear to have a major impact on the flexibility of food practices. Even among the youngest households, the majority have some culinary skills, recipes, and know-how that allow them to avoid monotony without resorting to processed foods. The implementation of those skills often requires specific circumstances: an alleviation of time constraints, for instance on weekends or holidays, or social contexts such as inviting guests for a meal.

Generally speaking, depending on age, household structure, time and money resources, lifestyles combine with location and access to food shops to define specific barriers to more sustainable practices. Moreover, the promotion of more sustainable food practices may follow different paths; in some patterns, the reduction of waste may be easier, whereas in others the development of local purchases may be the simplest option. It appears difficult, and maybe pointless, to find ways to push households into one pattern or another. Modifications to meanings, materials, and skills do not always require the same actions. The promotion of values linked to the protection of the environment in food practices is still weak in public discourse in France, although it has increased recently. The adoption of those values by any household may take time. As for materials, the development of a local, organic or ethical food supply at an affordable price, including in hypermarkets, should facilitate access to more sustainable food items for those who have neither the time nor the money to buy from specialized 
shops (patterns 1 and 3). In other patterns (2 and 4 to a lesser extent), quality is perceived as barely compatible with supermarkets, and the development of small shops should be privileged by local public policies. Our results finally show that the level of skills - for instance regarding the use of leftovers or their storage - differs among households, as well as the ability to mobilize them. On this last point, we should take into account the social dispositions of individuals, but also more general considerations of the organization of work and of sharing domestic tasks within households. Thus, this paper acknowledges the unequal distribution of the skills and materials that facilitate sustainable eating, and it highlights how these inequalities contribute to explaining variations in food practices and their meanings.

Acknowledgments We would like to thank Ana Perrin-Heredia who conducted the interviews, and Sophie Dubuisson-Quellier, Anne Lhuissier, and Marie Plessz for helpful comments on a previous draft of this paper. We are very grateful to the two anonymous reviewers who helped us revise the manuscript by their constructive remarks.

Funding The research was funded by the French Environment and Energy Management Agency, Ademe (Grant Dimensions Durables de l'Alimentation Domestique No 1110C003) and by the French Ministry for Economy, Environment and Sustainable Development (Grant 13-MUTS-MOVIDA-6CVS-019 2013-No CHORUS).

\section{Appendix}

\begin{tabular}{|c|c|c|c|c|}
\hline Pseudonym & Age & Occupational status & Family situation & $\begin{array}{l}\text { Place of } \\
\text { residence }\end{array}$ \\
\hline Viviane & 60 & $\begin{array}{l}\text { Primary schoolteacher on } \\
\text { sick leave }\end{array}$ & Married, two independent children & Paris \\
\hline Yves & 69 & $\begin{array}{l}\text { Former vice-president of an } \\
\text { advertisement agency }\end{array}$ & Married, two independent children & Paris \\
\hline Hélène & 59 & Part-time medical secretary & Married, three independent children & Paris \\
\hline Pierrette & 65 & $\begin{array}{l}\text { Former primary school } \\
\text { teacher }\end{array}$ & Married, two independent children & Paris \\
\hline Isabelle & 67 & Former bank employee & Married, one independent daughter, & Paris \\
\hline Georges & 69 & $\begin{array}{l}\text { Former employee in heat } \\
\text { engineering firm }\end{array}$ & $\begin{array}{l}\text { Remarried, one independent son, } \\
\text { one son at home aged } 23\end{array}$ & Paris \\
\hline Christiane & 61 & $\begin{array}{l}\text { Former English teacher } \\
\text { in high school }\end{array}$ & Married, two independent children & Paris \\
\hline Odile & 62 & Housewife & Married, two independent children & Paris \\
\hline Jacques & 62 & $\begin{array}{l}\text { Former employee in car } \\
\text { equipment firm }\end{array}$ & Married, two independent children & Paris \\
\hline Monette & 65 & Former journalist & Divorced, three independent children & Paris \\
\hline Bernard & 65 & $\begin{array}{l}\text { Former chemist in a } \\
\text { pharmaceutical company }\end{array}$ & Married, one independent child & Paris \\
\hline Chantal & 64 & Former secretary & Married, one independent child & Paris \\
\hline Corinne & 45 & Linguistics researcher & $\begin{array}{l}\text { Divorced, in couple, two children aged } \\
\quad 8 \text { and } 13\end{array}$ & Paris \\
\hline
\end{tabular}




\begin{tabular}{|c|c|c|c|c|}
\hline Pseudonym & Age & Occupational status & Family situation & $\begin{array}{l}\mathrm{P} \text { lace of } \\
\text { residence }\end{array}$ \\
\hline Naima & 38 & Tax inspector & $\begin{array}{l}\text { Civil partnership, one child } \\
\text { aged } 3\end{array}$ & Paris \\
\hline Stéphane & 30 & Tax inspector & $\begin{array}{l}\text { Civil partnership, one child } \\
\text { aged } 3\end{array}$ & Paris \\
\hline Valérie & 42 & $\begin{array}{l}\text { Part-time employee in a } \\
\text { home care association } \\
\text { and bar manager }\end{array}$ & $\begin{array}{l}\text { Divorced and remarried, two children } \\
\text { aged } 10 \text { and } 20\end{array}$ & Paris \\
\hline Nadège & 33 & Interior designer & Married, one child aged 2, pregnant & Paris \\
\hline Patricia & 45 & Part-time building caretaker & Married, one son aged 12 & Paris \\
\hline Elyane & 54 & Cook and housecleaner & Married, three independent children & Paris \\
\hline Anne & 44 & Part-time secretary & $\begin{array}{l}\text { Married, three children } \\
\text { aged } 14,9 \text { and } 6\end{array}$ & Noraville \\
\hline Renée & 73 & $\begin{array}{l}\text { Former housecleaner then } \\
\text { child-minder }\end{array}$ & $\begin{array}{l}\text { Married, two independent } \\
\text { children }\end{array}$ & Noraville \\
\hline André & 78 & Former mason & $\begin{array}{l}\text { Married, two independent } \\
\text { children }\end{array}$ & Noraville \\
\hline Christine & 56 & School principal & $\begin{array}{l}\text { Married, two independent } \\
\text { children, one at home aged } 19\end{array}$ & Noraville \\
\hline Huguette & 60 & Former schoolteacher & Two independent children & Noraville \\
\hline Eric & 39 & Student & Single & Noraville \\
\hline Roselyne & 60 & Specialized helper in pre-school & Divorced, two independent children & Noraville \\
\hline Gisèle & 60 & Former primary school teacher & $\begin{array}{l}\text { Married, two independent } \\
\text { children }\end{array}$ & Noraville \\
\hline Daniel & 64 & Former state employee & $\begin{array}{l}\text { Married, four independent } \\
\text { children }\end{array}$ & Noraville \\
\hline Nathalie & 45 & Spanish teacher & $\begin{array}{l}\text { In couple with a woman, one } \\
\text { child aged } 5\end{array}$ & Noraville \\
\hline Louise & 87 & $\begin{array}{l}\text { Former shorthand typist } \\
\text { then housewife }\end{array}$ & $\begin{array}{l}\text { Widow, eight independent } \\
\text { children }\end{array}$ & Noraville \\
\hline
\end{tabular}

Note: italics indicate that the interviewee is the spouse of the previously named person

\section{References}

Agence Bio (2017). Chiffres-clés de la bio - Le marché de la bio. Available online: http://www.agencebio. org/le-marche-de-la-bio-en-france. Accessed 20 Sep 2017.

Bourdieu, P. (1979). La Distinction: critique sociale du jugement. Paris: éditions de Minuit.

Brons, A., \& Oosterveer, P. (2017). Making sense of sustainability: A practice theories approach to buying food. Sustainability, 9(3), 467.

Burningham, K., Venn, S., Christie, I., Kackson, T., \& Gatersleben, B. (2014). New motherhood: A moment of change in everyday shopping practices? Young Consumers, 15(3), 211-226.

Cairns, K., Johnston, J., \& MacKendrick, N. (2013). Feeding the "organic child": Mothering through ethical consumption. Journal of Consumer Culture, 13(2), 97-118.

Carfagna, L. B., Dubois, E. A., Fitzmaurice, C., Ouimette, M. Y., Schor, J. B., Willis, M., \& Laidley, T. (2014). An emerging eco-habitus: The reconfiguration of high cultural capital practices among ethical consumers. Journal of Consumer Culture, 14(2), 158-178. 
Carrigan, M., Szmigin, I., \& Leek, S. (2006). Managing routine food choices in UK families: The role of convenience consumption. Appetite, 47, 372-383.

Cohen, M. J., Brown, H. S., \& Vergrat, P. J. (Eds.). (2013). Innovations in sustainable consumption. New economics, socio-technical transitions and social practices. Cheltenham, and Northampton: Edward Elgar.

DeVault, M. L. (1991). Feeding the family: The social organization of caring as gendered work. Chicago: University of Chicago Press.

Dubuisson-Quellier, S. (2009). La Consommation engagée. Paris: Presses de Sciences Po.

Dubuisson-Quellier, S., \& Gojard, S. (2016). Why are food practices not (more) environmentally friendly in France? The role of collective standards and symbolic boundaries in food practices. Environmental Policy and Governance, 26(2), 89-100.

Evans, D. (2011a). Blaming the consumer-once again: The social and material contexts of everyday food waste practices in some English households. Critical Public Health, 21(4), 429-440.

Evans, D. (2011b). Thrifty, green or frugal: Reflections on sustainable consumption in a changing economic climate. Geoforum, 42(5), 550-557.

Evans, D. (2012). Beyond the throwaway society to ordinary domestic practice: What can sociology say about food waste? Sociology, 46(1), 41-56.

Evans, D., McMeekin, A., \& Southerton, D. (2012). Sustainable consumption, behaviour change policies and theories of practice. In A. Warde \& D. Southerton (Eds.), The habits of consumption (pp. 113-129). Helsinki: Open Access Book Series of the Helsinki Collegium of Advanced Studies.

Halkier, B. (2009). Suitable cooking? Performances and positionings in cooking practices among Danish women'. Food, Culture and Society, 12(3), 357-377.

Halkier, B., \& Holm, L. (2008). Food consumption and political agency: On concerns and practices among Danish consumers. International Journal of Consumer Studies, 32, 667-674.

Halkier, B., \& Jensen, I. (2011). Methodological challenges in using practice theory in consumption research. Examples from a study on handling nutritional contestation of food consumption. Journal of Consumer Culture, 11(1), 101-123.

Hamilton, K. (2012). Low-income families and coping through brands: Inclusion or stigma? Sociology, 46(1), 74-90.

Hand, M., \& Shove, E. (2007). Condensing practices: Ways of living with a freezer. Journal of Consumer Culture, 7(1), 79-104.

Holm, L. (2003). Blaming the consumer: On the free choice of consumers and the decline in food quality in Denmark. Critical Public Health, 13(2), 139-154.

Hughner, R. S., McDonagh, P., Prothero, A., Shultz, C. J., \& Stanton, J. (2007). Who are organic food consumers? A compilation and review of why people purchase organic food. Journal of Consumer Behaviour, 6(2-3), 94-110.

Jabs, J., Devine, C. M., Bisogni, C. A., Farrell, T. J., Jastran, M., \& Wethington, E. (2007). Trying to find the quickest way: Employed mothers' constructions of time for food. Journal of Nutrition Education and Behavior, 39(1), 18-25.

Jackson, P., Perez del Aguila, R., Clarke, I., Hallsworth, A., de Kervenoael, R., \& Kirkup, M. (2006). Retail restructuring and consumer choice 2. Understanding consumer choice at the household level. Environment and Planning A, 38(1), 47-67.

Johnston, J., Szabo, M., \& Rodney, A. (2011). Good food, good people: Understanding the cultural repertoire of ethical consumption. Journal of Consumer Culture, 11(3), 293-318.

Johnston, J., Rodney, A., \& Szabo, M. (2012). Place, ethics, and everyday eating: A tale of two neighbourhoods. Sociology, 46(6), 1091-1108.

Kan, M. Y., Sullivan, O., \& Gershuny, J. (2011). Gender convergence in domestic work: Discerning the effects of interactional and institutional barriers from large-scale data. Sociology, 45(2), 234-251.

Keller, M., Halkier, B., \& Wilska, T. H. (2016). Policy and governance for sustainable consumption at the crossroads of theories and concepts. Environmental Policy and Governance, 26, 75-88.

Lahire, B. (2010 [1998]). The Plural Actor. Cambridge: Polity Press.

Lamine, C. (2008). Les Intermittents du bio. Pour une sociologie pragmatique des choix alimentaires émergents. Paris: éditions de la Maison des Sciences de l'Homme.

Larmet, G. (2002). L'Organisation des achats alimentaires. Cahiers d'économie et de sociologie rurales, 63, 51-84.

Micheletti, M., \& Stolle, D. (2012). Sustainable citizenship and the new politics of consumption. ANNALS of the American Academy of Political and Social Science, 644(1), 88-120.

Miller, D. (1998). A theory of shopping. Cambridge: Polity. 
Moisio, R., Arnould, E. J., \& Price, L. L. (2004). Between mothers and markets: Constructing family identity through homemade food. Journal of Consumer Culture, 4(3), 361-384.

Oosterveer, P., Guivant, J. S., \& Spaargaren, G. (2007). Shopping for green food in globalizing supermarkets: Sustainability at the consumption junction. In J. Pretty, A. Ball, T. Benton, et al. (Eds.), The SAGE handbook on environment and society (pp. 411-428). London: Sage.

Paddock, J. (2015). Invoking simplicity: 'Alternative' food and the reinvention of distinction. Sociologia Ruralis, 55, 22-40.

Paddock, J. (2017). Household consumption and environmental change: Rethinking the policy problem through narratives of food practice. Journal of Consumer Culture, 17(1), 122-139.

Plessz, M., \& Gojard, S. (2015). Fresh is best? Social position, cooking, and vegetable consumption in France. Sociology, 49(1), 172-190.

Plessz, M., Dubuisson-Quellier, S., Gojard, S., \& Barrey, S. (2016). How consumption prescriptions affect food practices: Assessing the roles of household resources and life course events. Journal of Consumer Culture, 16(1), 101-123.

Sahakian, M., \& Wilhite, H. (2014). Making practice theory practicable: Towards more sustainable forms of consumption. Journal of Consumer Culture, 14(1), 25-44.

Schatzki, T.R., Knorr Cetina, K., \& von Savigny, E. (Eds.) (2001). The practice turn in contemporary theory. London: Routledge.

Short, F. (2006). Kitchen secrets. The meaning of cooking in everyday life. Oxford, New York: Berg Publishers.

Shove, E., \& Southerton, D. (2000). Defrosting the freezer: From novelty to convenience. A narrative of normalization. Journal of Material Culture, 5(3), 301-319.

Shove, E., Pantzar, M., \& Watson, M. (2012). The dynamics of social practice: Everyday life and how it changes. London: Sage.

Southerton, D. (2006). Analysing the temporal organization of daily life: Social constraints, practices and their allocation. Sociology, 40(3), 435-454.

Southerton, D., \& Tomlinson, M. (2005). "Pressed for time"-the differential impacts of a "time squeeze". The Sociological Review, 53(2), 215-239.

Southerton, D., \& Yates, L. (2015). Exploring food waste through the lens of social practice theories: Some reflections on eating as a compound practice. In K. Ekstrom (Ed.), Waste management and sustainable consumption: Reflections on consumer waste (pp. 133-149). London: Routledge.

Spaargaren, G., \& Van Vliet, B. (2000). Lifestyles, consumption and the environment: The ecological modernization of domestic consumption. Environmental Politics, 9(1), 50-76.

Szabo, M. (2012). Foodwork or foodplay? Men's domestic cooking, privilege and leisure. Sociology, 47(4), 623-638.

Thompson, C. J. (1996). Caring consumers: Gendered consumption meanings and the juggling lifestyle. Journal of Consumer Research, 22(4), 388-407.

Truninger, M. (2011). Cooking with Bimby in a moment of recruitment: Exploring conventions and practice perspectives. Journal of Consumer Culture, 11(1), 37-59.

Venn, S., Burningham, K., Christie, I., \& Jackson, T. (2017). Consumption junkies or sustainable consumers: Considering the grocery shopping practices of those transitioning to retirement. Ageing and Society, 37(1), 14-38.

Warde, A. (2005). Consumption and theories of practice. Journal of Consumer Culture, 5(2), 131-153.

Warde, A. (2015). On the sociology of eating. Revue d'Etudes en Agriculture et Environnement, 96, 7-15.

Warde, A. (2016). The practice of eating. Cambridge: Polity Press.

Warde, A., \& Southerton, D. (Eds.). (2012). The habits of consumption. Open Access Book Series of the Helsinki Collegium of Advanced Studies: Helsinki.

Watson, M., \& Meah, A. (2013). Food, waste and safety: Negotiating conflicting social anxieties into the practices of domestic provisioning. The Sociological Review, 60(2), 102-120.

Wheeler, K. (2012). The practice of Fairtrade support. Sociology, 46(1), 126-141. 